University of Nebraska - Lincoln

DigitalCommons@University of Nebraska - Lincoln

\title{
Low-dose human chorionic gonadotropin may improve in vitro fertilization cycle outcomes in patients with low luteinizing hormone levels after gonadotropin-releasing hormone antagonist administration
}

\author{
Anthony M. Propst \\ Uniformed Services University of the Health Sciences, anthony.propst@usuhs.mil \\ Micah J. Hill \\ National Institutes of Health \\ Gordon Wright Bates \\ Wilford Hall Medical Center \\ Michelle Palumbo \\ Wilford Hall Medical Center \\ Anne K. Van Horne \\ Wilford Hall Medical Center

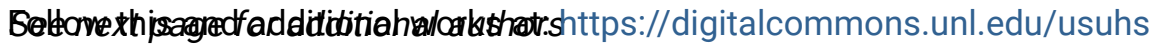 \\ Part of the Medicine and Health Sciences Commons
}

Propst, Anthony M.; Hill, Micah J.; Bates, Gordon Wright; Palumbo, Michelle; Van Horne, Anne K.; and Retzloff, Matthew g., "Low-dose human chorionic gonadotropin may improve in vitro fertilization cycle outcomes in patients with low luteinizing hormone levels after gonadotropin-releasing hormone antagonist administration" (2011). Uniformed Services University of the Health Sciences. 46.

https://digitalcommons.unl.edu/usuhs/46

This Article is brought to you for free and open access by the U.S. Department of Defense at DigitalCommons@University of Nebraska - Lincoln. It has been accepted for inclusion in Uniformed Services University of the Health Sciences by an authorized administrator of DigitalCommons@University of Nebraska Lincoln. 
Authors

Anthony M. Propst, Micah J. Hill, Gordon Wright Bates, Michelle Palumbo, Anne K. Van Horne, and Matthew g. Retzloff 


\title{
Low-dose human chorionic gonadotropin may improve in vitro fertilization cycle outcomes in patients with low luteinizing hormone levels after gonadotropin-releasing hormone antagonist administration
}

\author{
Anthony M. Propst, M.D., ${ }^{\text {a,b,c } M i c a h ~ J . ~ H i l l, ~ D . O ., ~}{ }^{\mathrm{a}}$ Gordon Wright Bates, M.D., ${ }^{\mathrm{b}}$ Michelle Palumbo, M.D., ${ }^{\mathrm{b}}$ \\ Anne K. Van Horne, M.D., ${ }^{\mathrm{b}}$ and Matthew G. Retzloff, M.D. ${ }^{\mathrm{b}}$ \\ ${ }^{a}$ Program in Reproductive and Adult Endocrinology, Eunice Kennedy Shriver National Institute of Child Health and Human \\ Development, National Institutes of Health, Bethesda, Maryland; ${ }^{\mathrm{b}}$ Division of Reproductive Endocrinology, Wilford Hall \\ Medical Center, San Antonio Uniformed Services Health Education Consortium, San Antonio, Texas; and ${ }^{\mathrm{c}}$ Uniformed $^{-}$ \\ Services University of the Health Sciences, Bethesda, Maryland
}

\begin{abstract}
Objective: To evaluate the effect of low levels of endogenous luteinizing hormone (LH) and low-dose human chorionic gonadotropin (hCG) supplementation on in vitro fertilization (IVF) cycle outcomes in a gonadotropinreleasing hormone $(\mathrm{GnRH})$ antagonist protocol.

Design: Retrospective study.

Setting: Military medical center.

Patient(s): General in vitro fertilization/embryo transfer (IVF-ET) population.

Intervention(s): Addition of low-dose urinary hCG to IVF stimulations using a recombinant follicle-stimulating hormone (FSH) and GnRH antagonist protocol.

Main Outcome Measure(s): Implantation and live-birth rates.

Result(s): As part of a larger cohort of 239 patients, 42 patients with LH levels $\leq 0.5 \mathrm{mIU} / \mathrm{mL}$ were evaluated. In the larger cohort, there were no differences in implantation and pregnancy rates between the recombinant FSH only $(\mathrm{n}=113)$ and the recombinant FSH with low-dose $\mathrm{hCG}$ supplementation $(\mathrm{n}=126)$ groups. In the FSH-only group, patients with LH levels $\leq 0.5 \mathrm{mIU} / \mathrm{mL}$ had decreased implantation rates (19\% vs. $42 \%$ ) and live-birth rates (25\% vs. 54\%) as compared with patients with LH levels $>0.5 \mathrm{mIU} / \mathrm{mL}$. Low LH patients in the recombinant FSH with low-dose urinary hCG group had statistically significantly higher implantation rates (54\% vs. $19 \%)$ and live-birth rates (64\% vs. $25 \%)$ as compared with patients with similar low LH levels in the recombinant FSH-only group. Conclusion(s): Endogenous LH levels $\leq 0.5 \mathrm{mIU} / \mathrm{mL}$ after GnRH antagonist treatment are associated with statistically significantly lower implantation and pregnancy rates in recombinant FSH-only cycles. The addition of lowdose urinary hCG results in improved implantation and live-birth rates in patients with low LH levels. (Fertil Steril ${ }^{\circledR}$ 2011;96:898-904. @2011 by American Society for Reproductive Medicine.)
\end{abstract}

Key Words: GnRH antagonist, IVF, low-dose uhCG, luteinizing hormone

The use of gonadotropin-releasing hormone (GnRH) antagonists in place of GnRH agonists has increased in in vitro fertilization (IVF)

Received May 11, 2011; revised June 27, 2011; accepted June 30, 2011; published online August 11, 2011.

A.M.P. has received consulting fees from Ferring. M.J.H. has nothing to disclose. G.W.B. has nothing to disclose. M.P. has nothing to disclose. A.K.V.H. has nothing to disclose. M.G.R. has nothing to disclose.

Supported in part by the Intramural research program of the Reproductive Biology and Medicine Branch, Eunice Kennedy Shriver National Institute of Child Health and Human Development, National Institutes of Health. The opinions and conclusions in this paper are those of the authors and are not intended to represent the official position of the Department of Defense, United States Air Force, United States Army or any other government agency.

Presented in part at the 53rd Annual Meeting of the Pacific Coast Reproductive Society, Indian Wells, CA, May 4-8, 2005, and the American College of Obstetricians and Gynecologists Armed Forces District Meeting, Louisville, KY, October, 28-31, 2007.

Reprint requests: Col. Anthony M. Propst, M.D., U.S.A.F., M.C., Uniformed Services University of the Health Sciences, 4301 Jones Bridge Road, Department of Obstetrics and Gynecology, Bethesda, Maryland 20814 (E-mail: anthony.propst@usuhs.mil). stimulation protocols (1). Unlike GnRH agonists, which require prolonged administration for pituitary suppression, GnRH antagonists allow for immediate suppression of pituitary gonadotropins (2). Additional advantages of GnRH antagonists include reducing the amount of exogenous gonadotropins required for IVF stimulation, shortening the duration of stimulation, and avoiding a gonadotropin flare (2). Rates of ovarian hyperstimulation syndrome are also decreased with GnRH antagonists (3). However, GnRH antagonists cause a rapid and profound inhibition of endogenous luteinizing hormone (LH) secretion (4-6), and this suppression occurs at a time when the follicle is most sensitive to $\mathrm{LH}$ activity. As described in the two-cell two-gonadotropin theory, normal follicular growth depends on both FSH and $\mathrm{LH}$, and it has been shown that low levels of LH may negatively affect pregnancy and implantation rates (7). Although the level of endogenous LH necessary for normal follicular development is unknown, the conclusions from several studies suggest that low levels of LH are associated with higher rates of early pregnancy loss (7-9).

The effect of GnRH antagonist on LH and estradiol levels before oocyte retrieval was studied in the ganirelix dose-finding study (10). 
It was shown that as the dose of ganirelix acetate increased, the serum LH and estradiol concentrations decreased in a dose-dependent manner (10). The number of good-quality embryos and the number of embryos transferred in the four different dosage groups were similar. However, the ongoing pregnancy rate was significantly lower in the groups with low levels of LH and estradiol before oocyte retrieval (10).

Donor IVF cycles using GnRH antagonists that were supplemented with recombinant LH had significantly higher fertilization and implantation rates (11). This suggests that GnRH antagonist use with recombinant FSH alone may have a negative impact on follicular growth and oocyte development. It is speculated that LH supplementation is necessary for normal granulosa cell function in GnRH antagonist cycles. These data indirectly suggest that low LH levels might lead to decreased implantation and pregnancy rates.

Recent evidence also shows that supplementation of GnRH antagonist cycles with human chorionic gonadotropin (hCG), a mimic of endogenous $\mathrm{LH}$, provides comparable pregnancy rates to cycles using standard ovulation-induction protocols $(12,13)$. The administration of hCG promotes follicular growth and oocyte maturation, thereby decreasing the amount of FSH needed for ovarian stimulation $(12,14,15)$. We previously published a study that showed that hCG supplementation results in lower medication costs and similar pregnancy rates compared with FSH-only stimulation for GnRH-antagonist IVF cycles (14). This retrospective study determines the effects of profound LH suppression after GnRH antagonist administration and determines whether low-dose hCG administration was beneficial in this patient population.

\section{MATERIALS AND METHODS}

This retrospective analysis examined 239 IVF or ICSI cycles in patients aged 23 to 40 years during the period May 2002 to October 2005. Institutional review board approval was obtained from Wilford Hall Medical Center. Inclusion criteria included all women who underwent ovarian hyperstimulation with recombinant FSH and ganirelix acetate (Merck) during this time period. Ovarian stimulation with recombinant FSH alone occurred until May 2004. After that all, patients were supplemented with low-dose hCG. An LH threshold of $\leq 0.5 \mathrm{mIU} / \mathrm{mL}$ was chosen to further group patients for analysis. The LH threshold of $\leq 0.5 \mathrm{mIU} / \mathrm{mL}$ was chosen based on data demonstrating that normogonadotropic patients with suppressed LH levels below this threshold have a higher rate of abortion and lower chance of live birth (8). Due to the retrospective nature of the study, a power analysis was not performed. The specific time frame for analysis was chosen, and data were not analyzed from other time periods so as not to introduce bias by choosing a time period that showed results in a specific direction.

Pituitary down-regulation was achieved with combined oral contraceptives (OCPs), which were started on day 5 of the cycle before ovarian stimulation. In the group using FSH alone, recombinant FSH (Gonal F, EMDSerono; or Follistim, Merck) was started at a dose of 150-600 IU per day (divided between a morning and evening dose) 5 days after discontinuation of combined OCP. In the group that was supplemented with low-dose hCG, recombinant FSH was started at a morning dose of 150 or 225 IU. Low-dose hCG (Pregnyl; Merck) was started concomitantly with recombinant FSH and was given in a daily evening dose of either 50 or 100 IU. The hCG dose was chosen to replace the evening FSH dose, and patients were given 50 IU of hCG if the FSH dose was less than $225 \mathrm{IU}$ or $100 \mathrm{IU}$ of hCG if the FSH dose was 225 IU or more. Transvaginal ultrasound was performed after 4 days of stimulation, and the dose of recombinant FSH and hCG was adjusted based on the number and size of follicles and the estradiol level.

A daily morning dose of $250 \mu \mathrm{g}$ of ganirelix acetate was started when lead follicles were 13 to $14 \mathrm{~mm}$ in mean diameter. When there were at least two follicles with a mean diameter of $\geq 18 \mathrm{~mm}$, with at least two additional follicles sized $\geq 10 \mathrm{~mm}$, hCG was administered (5,000-10,000 IU). Oocyte retrieval was performed 36 hours later, and the embryos were transferred either
3 or 5 days after retrieval, depending on embryo number and quality. Luteal phase support was maintained with $50 \mathrm{mg}$ of progesterone intramuscular injections daily beginning the evening after the oocyte retrieval and continuing until 7 to 8 weeks' estimated gestational age.

Serum LH and estradiol levels were measured before stimulation with FSH, before the start of the GnRH antagonist, at several intervals after the start of GnRH antagonist, and on the day of hCG administration for final oocyte maturation. All serum tests were drawn in the morning before the morning doses of gonadotropins or ganirelix acetate were administered. Luteinizing hormone and estradiol were measured by using an electrochemiluminescence immunoassay (Modular Analytics E170 module; Roche). The detection limits for $\mathrm{LH}$ and estradiol were $0.10 \mathrm{mIU} / \mathrm{mL}$ and $5.0 \mathrm{pg} / \mathrm{mL}$, respectively. The intra-assay and interassay coefficients of variation were $1.2 \%$ and $2.0 \%$, respectively, at the lowest mean dose of LH. The intra-assay and interassay coefficients of variation were $2.0 \%$ and $2.2 \%$, respectively, at a mean level of $3,715 \mathrm{pg} / \mathrm{mol}$. The LH assay used shows no crossreactivity with $\mathrm{FSH}$, thyroid-stimulating hormone (TSH), or hCG. Serum hCG levels were not measured in this study, including in the patients in the recombinant $\mathrm{FSH}+\mathrm{hCG}$ group.

\section{Statistical Methods}

All analyses were performed using SPSS 13 for Windows (SPSS, Inc.). Exploratory data analysis was initially performed to determine normality of the data. The parametric continuous variables were analyzed by using Student's $t$-test, and the results are expressed as mean \pm standard deviation. The nonparametric continuous or ordinal data were analyzed with the Mann-Whitney $U$ test. Percentages or rates were compared by using either chi-square or Fisher's exact test, as indicated.

\section{RESULTS}

A total of 239 IVF-ICSI cycles were analyzed. Forty-two cycles where patients had an LH level $\leq 0.5 \mathrm{mIU} / \mathrm{mL}$ were analyzed as part of this larger cohort. Seven cycles were canceled before embryo transfer, and two after oocyte retrieval had occurred. All of the canceled cycles were in the $\mathrm{LH}>0.5 \mathrm{IU} / \mathrm{mL}$ group. Patients were grouped based on stimulation with or without low-dose hCG and based on the lowest value of LH obtained at any point after the initiation of GnRH antagonist before the administration of hCG for final oocyte maturation using a threshold of $\mathrm{LH} \leq 0.5 \mathrm{mIU} / \mathrm{mL}$ or greater. Any $\mathrm{LH}$ value $\leq 0.5 \mathrm{mIU} / \mathrm{mL}$ at any time after the start of the GnRH antagonist qualified a patient to be placed in the low LH group. There were 113 cycles in the FSH-only group and 126 cycles in the FSH with low-dose hCG group. In the FSH-only group, 20 patients had LH levels $\leq 0.5 \mathrm{mIU} / \mathrm{mL}$. In the FSH with lowdose hCG group, 22 patients had LH levels $\leq 0.5 \mathrm{mIU} / \mathrm{mL}$.

Estradiol and LH levels were measured at baseline and at each ultrasound visit through the administration of the hCG trigger shot (Table 1). The baseline LH levels of the FSH-only and FSH with low-dose hCG groups were similar $(2.5 \pm 2.4$ vs. $2.5 \pm 2.4 \mathrm{mIU} /$ $\mathrm{mL}, P=.98$ ). Patients in the low $\mathrm{LH}$ group who received FSH only had lower baseline LH levels than did the patients in the normal LH group who received FSH only $(0.5 \pm 0.6$ vs. $2.9 \pm 2.5 \mathrm{mIU} /$ $\mathrm{mL}, P<.01)$. Similarly, patients in the low $\mathrm{LH}$ group who received low-dose hCG had lower baseline LH levels than did the patients in the normal LH group who received low-dose hCG $(1.1 \pm 2.2$ vs. $2.5 \pm 2.4 \mathrm{mIU} / \mathrm{mL}, P<.01)$. The baseline LH levels were not different between the FSH-only and FSH with low-dose hCG groups (0.33). The women in the FSH with low-dose hCG group were on average 1 year older $(P=.04)$.

There were no differences in implantation, spontaneous abortion, or live-birth rates between the groups receiving FSH only and FSH with low-dose hCG (see Table 1). The FSH with low-dose hCG group used less total FSH $(1,868$ vs. $2,899 \mathrm{IU}, P<.01)$ and had 


\begin{tabular}{|c|c|c|c|}
\hline \multicolumn{4}{|c|}{$\begin{array}{l}\text { Demographic and baseline characteristics and cycle } \\
\text { outcomes between the FSH-only group and FSH + low- } \\
\text { dose hCG group. }\end{array}$} \\
\hline & $\begin{array}{l}\text { FSH-only } \\
\text { group } \\
(n=113)\end{array}$ & $\begin{array}{l}\text { FSH }+ \\
\text { low-dose } \\
\text { hCG group } \\
(n=126)\end{array}$ & $\begin{array}{c}P \\
\text { value }\end{array}$ \\
\hline Age $(y)$ & $32.8 \pm 3.5$ & $33.8 \pm 3.6$ & .04 \\
\hline Day-3 LH (mlU/mL) & $2.5 \pm 2.4$ & $2.5 \pm 2.4$ & .94 \\
\hline $\begin{array}{l}\text { FSH administered } \\
\text { (IU) }\end{array}$ & $2,898 \pm 1,010$ & $1,868 \pm 573$ & $<.01$ \\
\hline $\begin{array}{l}\text { HCG administered } \\
\text { (IU) }\end{array}$ & 0 & $600 \pm 266$ & \\
\hline $\begin{array}{l}\text { Peak estradiol } \\
(\mathrm{pg} / \mathrm{mL})^{\mathrm{a}}\end{array}$ & $2,098 \pm 1,183$ & $3,142 \pm 1717$ & $<.01$ \\
\hline Oocytes retrieved & $14.9 \pm 9.0$ & $12.4 \pm 7.1$ & .02 \\
\hline Embryos & $8.9 \pm 6.3$ & $7.8 \pm 5.1$ & .15 \\
\hline Embryos transferred & $2.2 \pm 0.5$ & $2.2 \pm 0.5$ & .46 \\
\hline Implantation (\%) & 38 & 36 & .75 \\
\hline $\begin{array}{l}\text { Spontaneous } \\
\text { abortion (\%) }\end{array}$ & 7 & 3 & .23 \\
\hline $\begin{array}{l}\text { Clinical pregnancy } \\
(\%)\end{array}$ & 55 & 55 & .99 \\
\hline Live birth (\%) & 48 & 50 & .59 \\
\hline \multicolumn{4}{|c|}{$\begin{array}{l}\text { Note: } \mathrm{FSH}=\text { follicle-stimulating hormone; } \mathrm{hCG}=\text { human chorionic go- } \\
\text { nadotropin; } \mathrm{LH}=\text { luteinizing hormone. } \\
\text { a Peak estradiol levels defined as estradiol on the day of } 5,000 \text { or } 10,000 \\
\text { IU hCG. }\end{array}$} \\
\hline \multicolumn{4}{|c|}{ Propst. Low LH levels in IVF. Fertil Steril 2011.} \\
\hline
\end{tabular}

higher peak estradiol levels $(3,142$ vs. $2,098 \mathrm{pg} / \mathrm{mL}, P<.01)$ than the FSH-only group.

Table 2 shows the IVF cycle outcomes within the FSH-only group, comparing patients with an LH level $\leq 0.5 \mathrm{mIU} / \mathrm{mL}$ to those above this threshold. Patients with the low LH nadir had more oocytes retrieved ( 21 vs. $13, P<.01)$ and more embryos (13.1 vs.

\begin{tabular}{|c|c|c|c|}
\hline \multicolumn{4}{|c|}{$\begin{array}{l}\text { Comparison of outcomes in the FSH-only group between } \\
\text { patients with an LH nadir of } \leq 0.5 \mathrm{mlU} / \mathrm{mL} \text { versus those } \\
\text { with an LH nadir of }>0.5 \mathrm{mIU} / \mathrm{mL} \text {. }\end{array}$} \\
\hline & $\begin{array}{l}\text { LH nadir } \\
\leq 0.5 \mathrm{mlU} / \mathrm{mL} \\
\quad(\mathrm{n}=20)\end{array}$ & $\begin{array}{l}\text { LH nadir } \\
>0.5 \mathrm{mIU} / \mathrm{mL} \\
\quad(\mathrm{n}=93)\end{array}$ & $\begin{array}{c}P \\
\text { value }\end{array}$ \\
\hline Age (y) & $33.8 \pm 3.1$ & $32.6 \pm 3.5$ & .17 \\
\hline Peak estradiol & $1,972 \pm 1,059$ & $2,126 \pm 1,213$ & .06 \\
\hline Oocytes retrieved & $21.4 \pm 10.0$ & $13.4 \pm 6.3$ & $<.01$ \\
\hline Embryos & $13.1 \pm 6.7$ & $7.9 \pm 5.8$ & $<.01$ \\
\hline Embryos transferred & $2.1 \pm 0.3$ & $2.2 \pm 0.6$ & .57 \\
\hline Implantation (\%) & 19 & 42 & $<.01$ \\
\hline $\begin{array}{l}\text { Spontaneous } \\
\text { abortion (\%) }\end{array}$ & 3 & 8 & .69 \\
\hline Clinical pregnancy (\%) & 30 & 59 & .03 \\
\hline Live birth (\%) & 25 & 54 & $<.01$ \\
\hline
\end{tabular}

Note: $\mathrm{FSH}=$ follicle-stimulating hormone; $\mathrm{LH}=$ luteinizing hormone.

Propst. Low LH levels in IVF. Fertil Steril 2011.

\begin{tabular}{|c|c|c|c|}
\hline \multicolumn{4}{|c|}{$\begin{array}{l}\text { Comparison of cycle outcomes between patients with } \\
\text { nadir LH levels } \leq 0.5 \mathrm{mIU} / \mathrm{mL} \text { in the FSH only group and the } \\
\text { FSH + low-dose } \mathrm{hCG} \text { group. }\end{array}$} \\
\hline & $\begin{array}{l}\text { FSH only } \\
(n=20)\end{array}$ & $\begin{array}{c}\text { FSH + } \\
\text { low-dose } \\
\text { hCG }(n=22)\end{array}$ & $\begin{array}{c}P \\
\text { value }\end{array}$ \\
\hline Age $(y)$ & $33.8 \pm 3.1$ & $33.1 \pm 3.9$ & .50 \\
\hline Peak estradiol & $1,972 \pm 1,059$ & $3,373 \pm 1,504$ & $<.01$ \\
\hline Oocytes retrieved & $21.4 \pm 10.0$ & $13.5 \pm 6.3$ & $<.01$ \\
\hline Embryos & $13.1 \pm 6.7$ & $8.6 \pm 5.0$ & .02 \\
\hline Embryos transferred & $2.1 \pm 0.3$ & $2.1 \pm 0.4$ & .94 \\
\hline Implantation (\%) & 19 & 54 & $<.01$ \\
\hline $\begin{array}{l}\text { Spontaneous abortion } \\
\text { (\%) }\end{array}$ & 5 & 5 & .99 \\
\hline Clinical pregnancy (\%) & 30 & 68 & $<.01$ \\
\hline Live birth (\%) & 25 & 64 & .01 \\
\hline \multicolumn{4}{|c|}{$\begin{array}{l}\text { Note: } \mathrm{FSH}=\text { follicle-stimulating hormone; } \mathrm{hCG}=\text { human chorionic go- } \\
\text { nadotropin; } \mathrm{LH}=\text { luteinizing hormone. }\end{array}$} \\
\hline
\end{tabular}

7.9, $P<.01)$. Despite having more oocytes and embryos, the low LH patients had statistically significantly lower implantation rates (19\% vs. $42 \%, P<.01$ ), clinical pregnancy rates (30\% vs. $59 \%$, $P<.01)$, and live-birth rates $(25 \%$ vs. $54 \%, P<.01)$ (Table 2$)$.

Table 3 shows the IVF cycle outcomes in patients with LH levels $\leq 0.5 \mathrm{mIU} / \mathrm{mL}$, comparing those in the FSH-only group and those in the FSH with low-dose hCG group. The patients receiving FSH only had higher numbers of oocytes retrieved (21 vs. 13, $P<.01)$ and lower peak estradiol levels $(1,972$ vs. $3,373 \mathrm{pg} / \mathrm{mL}$, $P<.01)$ as compared with patients receiving FSH with low-dose hCG. Patients receiving low-dose hCG had higher implantation rates (54\% vs. $19 \%, P<.01$ ), clinical pregnancy rates $(68 \%$ vs. $30 \%$, $P<.01)$, and higher live-birth rates $(64 \%$ vs. $25 \%, P=.01)$. Patients receiving FSH stimulation only who had $\mathrm{LH}$ levels $\leq 0.5 \mathrm{mIU} / \mathrm{mL}$ had statistically significantly lower implantation and live-birth rates than all other patient groups (Fig. 1). Patients with LH levels $\leq 0.5$ $\mathrm{mIU} / \mathrm{mL}$ who received low-dose hCG supplementation had outcomes similar to patients with normal LH levels (see Fig. 1).

\section{DISCUSSION}

Our data demonstrate a negative impact of suppressed LH levels below a threshold of $\leq 0.5 \mathrm{mIU} / \mathrm{mL}$ before final oocyte maturation in $\mathrm{GnRH}$ antagonist cycles. The negative impact of suppressed LH activity was demonstrated by reduced implantation and live-birth rates. We also show that the negative impact of suppressed LH levels can be overcome with the addition of LH activity in the form of lowdose hCG. When patients were not supplemented with low-dose hCG, there was a clear difference in outcomes between patients with LH nadir levels $\leq 0.5 \mathrm{mIU} / \mathrm{mL}$ compared with those above this level. Lower implantation rates and lower live-birth rates were seen in the low LH group as compared with the group with higher resting LH levels. Conversely, when hCG was given to patients with low LH levels, their outcomes were improved and were similar to patients without profound LH suppression. Low LH patients given hCG had higher implantation rates and higher live-birth rates when compared with low LH patients not supplemented with hCG. Our data also demonstrated that patients with LH nadir levels $\leq 0.5$ 


\section{FIGURE 1}

Comparison of implantation and live-birth rates. Group comparisons made between patients receiving follicle-stimulating hormone (FSH) only with luteinizing hormone (LH) $\leq 0.5 \mathrm{mlU} / \mathrm{mL}$ (blue bar), patients receiving FSH only with $\mathrm{LH}$ nadir $>0.5 \mathrm{mlU} / \mathrm{mL}$ (red bar), and patients receiving FSH + low-dose hCG with LH nadir $\leq 0.5 \mathrm{mlU} / \mathrm{mL}$ (green bar). The addition of low-dose hCG in patients with $\mathrm{LH}$ levels $\leq 0.5 \mathrm{mIU} / \mathrm{mL}$ resulted in outcomes similar to those of patients with normal LH levels.

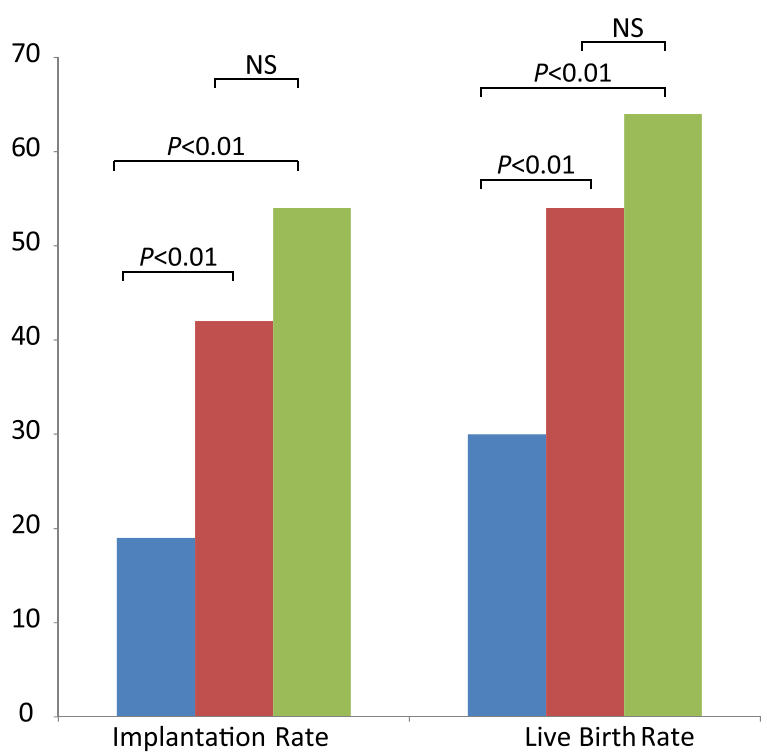

FSH only with $\mathrm{LH} \leq 0.5 \mathrm{mIU} / \mathrm{ml}$

FSH only with $\mathrm{LH}>0.5 \mathrm{mIU} / \mathrm{ml}$

FSH + low-dose hCG only with $\mathrm{LH} \leq 0.5 \mathrm{mIU} / \mathrm{ml}$

Propst. Low LH levels in IVF. Fertil Steril 2011.

$\mathrm{mIU} / \mathrm{mL}$ had lower LH levels at baseline measurement than patients with $\mathrm{LH}$ nadir levels $>0.5 \mathrm{mIU} / \mathrm{mL}$. This suggests the possibility that patients who had a greater degree of LH suppression after OCP treatment were at risk for more profound LH suppression after GnRH antagonist treatment.

The concept of an LH threshold below which negative reproductive outcomes are seen has been well documented $(8,16-19)$. Our data support the theory that there is an LH threshold below which adverse effects are seen in human assisted reproduction. Studies on patients with hypothalamic amenorrhea have shown the addition of LH is necessary to achieve appropriate follicular and endometrial development (20-25). However, it has also been shown that many normogonadotropic patients can be stimulated successfully with FSH alone in both GnRH antagonist and GnRH agonist cycles (26-31). Presumably this is because many patients have resting levels of $\mathrm{LH}$ that are adequate to initiate steroidogenesis and promote oocyte maturity, despite GnRH analogue down-regulation (32). There remains a cohort of patients who develop profound LH suppression with GnRH analogue treatment. A recent paper evaluating practices at consistently high-performing IVF programs in the United States showed these programs use a mixture of LH and FSH during ovarian stimulation (33). Studies have shown that patients with low LH levels have decreased estradiol levels, retarded follicular growth, decreased pregnancy rates, and increased miscarriage rates $(8,16-18)$. The
LH threshold has been demonstrated to be between 0.5 and $1.2 \mathrm{mIU} / \mathrm{mL}$ in prior studies $(8,16,18)$. We believe patients below an LH threshold of 0.6 mIU benefit from the addition of LH activity during IVF stimulation.

Both hCG and LH have the same alpha subunit, and both bind to and activate postreceptor changes on the $\mathrm{LH} / \mathrm{hCG}$ receptor. The beta subunit of hCG has a different structure and glycosylation pattern than $\mathrm{LH}$, resulting in a sixfold increased affinity for the $\mathrm{LH} / \mathrm{hCG}$ receptor and longer half-life (13). We have previously shown that a low-dose hCG protocol also reduces IVF stimulation costs by an average of $\$ 600$ per cycle by reducing the amount of FSH needed to complete stimulation (14). As low-dose hCG is a cost effective alternative for adding LH activity and has demonstrable biologic activity at low doses, we chose low-dose hCG as the source of LH activity in our stimulation protocol. Other sources of LH activity include human menopausal gonadotropin (hMG) and recombinant $\mathrm{LH}$.

Our data show an increase in live-birth rates by increasing implantation rates in patient with low LH levels who receive lowdose hCG. It is possible that hCG either acts to increase the quality of the oocytes themselves or that hCG is acting on the endometrium to increase the likelihood of implantation. Luteinizing hormone acts on the granulosa cells to generate increased substrate for estradiol production. In our study and others, patients exposed to $\mathrm{LH} / \mathrm{hCG}$ have higher estradiol levels and generate more estradiol per follicle (26, 28, 29, 34-41). Additionally, LH acts through postreceptor paracrine factors such as amphiregulin and epiregulin. These epidermal growth factor-like factors cause cumulous cell expansion and trigger the oocyte to reenter the cell cycle and proceed through meiosis I and have been shown to increase the maturation rate of in vitro matured germinal vesicle-stage oocytes (42-44). Through stimulation of the $\mathrm{LH} / \mathrm{hCG}$ receptor, low-dose hCG may result in a more reproductively competent oocyte.

The $\mathrm{LH} / \mathrm{hCG}$ receptor has also been shown to be present in the endometrium and to increase during the peri-implantation window. Apoptosis of endometrial stromal cells can also be reduced by the administration of hCG $(45,46)$. Additionally, hCG messenger RNA (mRNA) is transcribed as early as the two-cell stage of the embryo (47), and the hCG protein is already being secreted by the embryo before implantation $(48,49)$. Thus, there appears to be an effect of hCG on the regulation of the endometrium and on implantation (50-53). The addition of LH activity in the form of hMG or recombinant $\mathrm{LH}$ has been associated with an increase in implantation rates $(11,38,54,55)$, although other studies have not confirmed this finding $(56,57)$. In a recent randomized controlled trial, Bosch et al. (58) showed that the addition of recombinant LH to recombinant FSH in GnRH antagonist cycles results in improved implantation rates in patients 36 to 39 years old but not in younger patients. Our data show a similar implantation rate between both treatment groups when $\mathrm{LH}$ levels were $>0.5 \mathrm{mIU} / \mathrm{mL}$. However, patients with low LH levels had higher implantation rates when supplemented with low-dose hCG. This suggests that the addition of low-dose hCG may improve the implantation process in patients with profound $\mathrm{LH}$ suppression in a GnRH antagonist cycle.

Our data are consistent with the literature in showing that patients supplemented with $\mathrm{LH} / \mathrm{hCG}$ have a greater amount of estradiol production, a lower number of follicles that develop, and a decreased amount of FSH needed to complete IVF stimulation. In several studies, Filicori et al. (59-61) have shown that addition of LH/hCG to ovarian stimulation results in a regression of small ovarian follicles without affecting the number of intermediate $(10-14 \mathrm{~mm})$ or large $(>14 \mathrm{~mm})$ follicles. These data are confirmed in several randomized controlled trials showing that the addition of either 
hMG or recombinant $\mathrm{LH}$ to ovarian stimulation reduces the number of developing follicles and oocytes retrieved (28, 29, 34, 56, 57). However this reduction in follicle number does not seem to decrease the embryo yield or quality. In fact, a meta-analysis evaluating recombinant $\mathrm{LH}$ supplementation found $\mathrm{LH}$ activity to be associated with a higher number of mature oocytes retrieved (62). This is consistent with the experiments from Filicori's group showing that LH activity decreases the development of small oocytes but does not decrease the pool of larger follicles. The LH/hCG activity increases the activity of the enzymes involved in steroid production, leading to increased substrate for conversion to estradiol. Several randomized controlled trials have also confirmed this positive association with hMG, recombinant $\mathrm{LH}$, and hCG and increased peak estradiol levels $(12,13,15,26,28,29,34-41,63)$. Our study is consistent with these data in demonstrating that the addition of LH activity decreases the overall oocyte yield and increases the peak estradiol levels.

Although our data show a significant improvement in live-birth rates in patients with suppressed LH levels by the addition of lowdose hCG, the overall live-birth rate was similar between both treatment groups when all patients were included ( $48 \%$ vs. $50 \%, P=.59)$. This $2 \%$ difference in the live-birth rate is similar to that seen in two meta-analyses evaluating the benefit of $\mathrm{LH} / \mathrm{hCG}$ activity in the form of hMG $(64,65)$. Both meta-analyses show a $3 \%$ to $4 \%$ increase in live-birth rate in the hMG-treated groups; however, over 2,000 patients were required to find statistical significance $(64,65)$. Power analysis of our own data suggests that approximately 5,000 patients would have to be randomized to show a statistically significant improvement in the live-birth rate if all patients were included. We were able to demonstrate a statistically significant difference in implantation and live-birth rate by analyzing just patients with profound LH suppression.

Potential weaknesses of this study include its retrospective design and relatively small sample size. Because the study compares patients before and after a protocol change in 2004 (the addition of low-dose hCG to the stimulation protocol), potential bias exists if improvement in other assisted reproduction techniques (ART) were introduced during this time. We are not aware of any other major changes in our ART protocol during this study period that may have significantly introduced such bias. It should also be noted that there are studies that do not support the concept that low LH levels in GnRH antagonist cycles are associated with poor IVF outcomes $(2,66,67)$. For example, using the same threshold of $\leq 0.5$ $\mathrm{mIU} / \mathrm{mL}$, Merviel et al. (67) did not find any significant detrimental effect of low LH levels. Possible explanations for these differing findings include OCP pretreatment, daily versus single dose GnRH antagonist administration (4), variability in the sensitivities of commercially available LH assays, and the fact that biochemical assays of LH do not always accurately reflect LH bioactivity (68). It is also possible that the time of day when the GnRH antagonist is administered and when LH is measured could affect outcomes. When LH levels were measured in a single patient every 15 minutes for 24 hours, it was noted that in a single day the $\mathrm{LH}$ levels varied from $1.8 \mathrm{mIU} / \mathrm{mL}$ just before antagonist treatment to $0.5 \mathrm{mIU} / \mathrm{mL}$ 6 hours later (5). When the discriminating thresholds for considering adequate LH levels are so low, it is possible that the timing of medication administration and serum hormone evaluation could influence results. It should also be noted that our cohort of patients was pretreated with OCPs. It is possible that the benefit of lowdose hCG in GnRH antagonist cycles is limited to patients pretreated with OCPs. Caution should be taken in extrapolating our data to nonOCP treatment cycles and further research to clarify this issue would be beneficial.

Our data show that profound suppression of LH levels after $\mathrm{GnRH}$ antagonist administration is associated with reduced implantation and live-birth rates. The addition of low-dose hCG to the IVF stimulation protocol improves implantation and live-birth rates in patients with low LH levels. This is consistent with a recent meta-analysis that suggests a trend toward an increase in clinical pregnancy rates in low-dose hCG protocols during $\mathrm{GnRH}-$ antagonist cycles (69). However, there remains a lack of welldesigned, randomized, controlled trials evaluating this protocol, and additional research is warranted.

Acknowledgments: The authors thank Anneke Bush, Ph.D., who provided the statistical analysis for this study, and Nancy Lo, M.D., and Nancy Arthur, R.N., who collected and entered the data.

\section{REFERENCES}

1. Olivennes F, Cunha-Filho JS, Fanchin R, Bouchard P, Frydman R. The use of GnRH antagonists in ovarian stimulation. Hum Reprod Update 2002;8:279-90.

2. Tarlatzis BC, Fauser BC, Kolibianakis EM, Diedrich K, Devroey P, Brussels Gn RHAC. GnRH antagonists in ovarian stimulation for IVF. Hum Reprod Update 2006;12:333-40.

3. Griesinger G. Ovarian hyperstimulation syndrome prevention strategies: use of gonadotropin-releasing hormone antagonists. Semin Reprod Med 2010;28:493-9.

4. Duijkers IJM, Klipping C, Willemsen WNP, Krone D, Schneider E, Niebch G, et al. Single and multiple dose pharmacokinetics and pharmacodynamics of the gonadotrophin-releasing hormone antagonist Cetrorelix in healthy female volunteers. Hum Reprod 1998;13:2392-8.

5. Griesinger G, Dawson A, Schultze-Mosgau A, Finas D, Diedrich K, Felberbaum R. Assessment of luteinizing hormone level in the gonadotropinreleasing hormone antagonist protocol. Fertil Steril 2006;85:791-3.

6. Sommer L, Zanger K, Dyong T, Dorn C, Luckhaus T, Diedrich $\mathrm{K}$, et al. 7-Day administration of the gonadotropin-releasing-hormone antagonist cetrorelix in normal cycling women. Eur $\mathrm{J}$ Endocrinol 1994;131:280-5.

7. Esposito MA, Barnhart KT, Coutifaris C, Patrizio P. Role of periovulatory luteinizing hormone concentrations during assisted reproductive technology cycles stimulated exclusively with recombinant folliclestimulating hormone. Fertil Steril 2001;75:519-24.

8. Westergaard LG, Laursen SB, Andersen CY. Increased risk of early pregnancy loss by profound suppression of luteinizing hormone during ovarian stimulation in normogonadotrophic women undergoing assisted reproduction. Hum Reprod 2000;15:1003-8.

9. Meldrum DR, Scott RT, Levy MJ, Alper MM, Noyes N. Oral contraceptive pretreatment in women undergoing controlled ovarian stimulation in ganirelix acetate cycles may, for a subset of patients, be associated with low serum luteinizing hormone levels, reduced ovarian response to gonadotropins, and early pregnancy loss. Fertil Steril 2009;91:1963-5.

10. Mannaerts B, Devroey P, Abyholm T, Diedrich K, Hillensjo T, Hedon B, et al. A double-blind, randomized, dose-finding study to assess the efficacy of the gonadotrophin-releasing hormone antagonist ganire- lix (Org 37462) to prevent premature luteinizing hormone surges in women undergoing ovarian stimulation with recombinant follicle stimulating hormone (Puregon). Hum Reprod 1998;13:3023-31.

11. Acevedo B, Sanchez M, Gomez JL, Cuadros J, Ricciarelli E, Hernandez ER. Luteinizing hormone supplementation increases pregnancy rates in gonadotropin-releasing hormone antagonist donor cycles. Fertil Steril 2004;82:343-7.

12. Serafini P, Yadid I, Motta ELA, Alegretti JR, Fioravanti J, Coslovsky M. Ovarian stimulation with daily late follicular phase administration of lowdose human chorionic gonadotropin for in vitro fertilization: a prospective, randomized trial. Fertil Steril 2006;86:830-8.

13. Filicori M, Cognigni GE, Gamberini E, Parmegiani L, Troilo E, Roset B. Efficacy of low-dose human chorionic gonadotropin alone to complete controlled ovarian stimulation. Fertil Steril 2005;84:394-401.

14. Van Horne AK, Bates GW, Robinson RD, Arthur NJ, Propst AM. Recombinant follicle-stimulating hormone (rFSH) supplemented with low-dose human chorionic gonadotropin compared with rFSH alone for ovarian stimulation for in vitro fertilization. Fertil Steril 2007;88:1010-3. 
15. Koichi K, Yukiko N, Shima K, Sachiko S. Efficacy of low-dose human chorionic gonadotropin (hCG) in a GnRH antagonist protocol. J Assist Reprod Genet 2006;23:223-8.

16. Lahoud R, Al-Jefout M, Tyler J, Ryan J, Driscoll G. A relative reduction in mid-follicular $\mathrm{LH}$ concentrations during GnRH agonist IVF/ICSI cycles leads to lower live birth rates. Hum Reprod 2006;21:2645-9.

17. O'Dea L, O'Brien F, Currie K, Hemsey G. Follicular development induced by recombinant luteinizing hormone ( $\mathrm{LH})$ and follicle-stimulating hormone (FSH) in anovulatory women with LH and FSH deficiency: evidence of a threshold effect. Curr Med Res Opin 2008;24:2785-93.

18. Fleming R, Chung CC, Yates RWS, Coutts JRT. Purified urinary follicle stimulating hormone induces different hormone profiles compared with menotrophins, dependent upon the route of administration and endogenous luteinizing hormone activity. Hum Reprod 1996;11:1854-8.

19. Shoham Z. The clinical therapeutic window for luteinizing hormone in controlled ovarian stimulation. Fertil Steril 2002;77:1170-7.

20. Schoot DC, Harlin J, Shoham Z, Mannaerts B, Lahlou N, Bouchard P, et al. Recombinant human follicle-stimulating-hormone and ovarian response in gonadotropin-deficient women. Hum Reprod 1994;9:1237-42.

21. Shoham Z, Smith H, Yeko T, O'Brien F, Hemsey G, O'Dea L. Recombinant LH (lutropin alfa) for the treatment of hypogonadotrophic women with profound LH deficiency: a randomized, double-blind, placebo-controlled, proof-of-efficacy study. Clin Endocrinol 2008;69:471-8.

22. Kaufmann R, Dunn R, Vaughn T, Hughes G, O'Brien F, Hemsey G, et al. Recombinant human luteinizing hormone, lutropin alfa, for the induction of follicular development and pregnancy in profoundly gonadotrophin-deficient women. Clin Endocrinol 2007;67:563-9.

23. Couzinet B, Lestrat N, Brailly S, Forest M, Schaison G. Stimulation of ovarian follicular maturation with pure follicle-stimulating-hormone in women with gonadotropin-deficiency. J Clin Endocrinol Metab 1988;66:552-6.

24. Crowley WF, McArthur JW. simulation of the normal menstrual-cycle in Kallman syndrome by pulsatile administration of luteinizing-hormone-releasing hormone (LHRH). J Clin Endocrinol Metab 1980;51:173-5.

25. European Recombinant Human LHSG. Recombinant human luteinizing hormone $(\mathrm{LH})$ to support recombinant human follicle-stimulating hormone (FSH)-induced follicular development in $\mathrm{LH}-$ and FSH-deficient anovulatory women: a dose-finding study. J Clin Endocrinol Metab 1998;83:1507-14.

26. Kilani Z, Dakkak A, Ghunaim S, Cognigni GE, Tabarelli C, Parmegiani L, et al. A prospective, randomized, controlled trial comparing highly purified hMG with recombinant FSH in women undergoing ICSI: ovarian response and clinical outcomes. Hum Reprod 2003;18:1194-9.

27. Ismail AF, Hesham AI, Salah Z, Khaled M, Fouad N, Ashraf N, et al. A prospective comparative study on IVF outcomes with either purified FSH or human menopausal gonadotrophin in downregulated normogonadotrophic women. Gynecol Obstet Invest 2002;53:220-3.

28. Andersen AN, Devroey P, Arce JC, Grp M. Clinical outcome following stimulation with highly purified hMG or recombinant FSH in patients undergoing IVF: a randomized assessor-blind controlled trial. Hum Reprod 2006;21:3217-27.

29. Bosch E, Vidal C, Labarta E, Simon C, Remohi J, Pellicer A. Highly purified hMG versus recombinant
FSH in ovarian hyperstimulation with GnRH antagonists-a randomized study. Hum Reprod 2008;23:2346-51.

30. Ng EHY, Lau EYL, Yeung WSB, Ho PC. HMG is as good as recombinant human FSH in terms of oocyte and embryo quality: a prospective randomized trial. Hum Reprod 2001;16:319-25.

31. Rashidi BH, Sarvi F, Tehrani ES, Zayeri F, Movahedin M, Khanafshar N. The effect of hMG and recombinant human FSH on oocyte quality: a randomized single-blind clinical trial. Eur J Obstet Gynecol Reprod Biol 2005;120:190-4.

32. Chappel SC, Howles C. Reevaluation of the roles of luteinizing-hormone and follicle-stimulatinghormone in the ovulatory process. Hum Reprod 1991;6:1206-12.

33. Van Voorhis BJ, Thomas M, Surrey ES, Sparks A. What do consistently high-performing in vitro fertilization programs in the US do? Fertil Steril 2010;94:1346-9.

34. Westergaard LG, Erb K, Laursen SB, Rex S, Rasmussen PE. Human menopausal gonadotropin versus recombinant follicle-stimulating hormone in normogonadotropic women down-regulated with a gonadotropin-releasing hormone agonist who were undergoing in vitro fertilization and intracytoplasmic sperm injection: a prospective randomized study. Fertil Steril 2001;76:543-9.

35. Levi-Setti PE, Cavagna M, Bulletti C. Recombinant gonadotrophins associated with GnRH antagonist (cetrorelix) in ovarian stimulation for ICSI: Comparison of r-FSH alone and in combination with r-LH. Eur J Obstet Gynecol Reprod Biol 2006;126:212-6.

36. Tarlatzis B, Tavmergen E, Szamatowicz M, Barash A, Amit A, Levitas E, et al. The use of recombinant human LH (lutropin alfa) in the late stimulation phase of assisted reproduction cycles: a double-blind, randomized, prospective study. Hum Reprod 2006;21:90-4.

37. Griesinger G, Schultze-Mosgau A, Dafopoulos K, Schroeder A, Schroer A, von Otte S, et al. Recombinant luteinizing hormone supplementation to recombinant follicle-stimulating hormone induced ovarian hyperstimulation in the GnRH-antagonist multiple-dose protocol. Hum Reprod 2005;20: 1200-6.

38. Lisi F, Rinaldi L, Fishel S, Caserta D, Lisi R, Campbell A. Evaluation of two doses of recombinant luteinizing hormone supplementation in an unselected group of women undergoing follicular stimulation for in vitro fertilization. Fertil Steril 2005;83:309-15.

39. De Placido G, Alviggi C, Perino A, Strina I, Lisi F, Fasolino A, et al. Recombinant human LH supplementation versus recombinant human FSH (rFSH) step-up protocol during controlled ovarian stimulation in normogonadotrophic women with initial inadequate ovarian response to $\mathrm{rFSH}$ : a multicentre, prospective, randomized controlled trial. Hum Reprod 2005;20:390-6.

40. Sauer MV, Thornton MH, Schoolcraft W, Frishman GN. Comparative efficacy and safety of cetrorelix with or without mid-cycle recombinant $\mathrm{LH}$ and leuprolide acetate for inhibition of premature LH surges in assisted reproduction. Reprod Biomed Online 2004;9:487-93.

41. Cedrin-Durnerin I, Grange-Dujardin D, Laffy A, Parneix I, Massin N, Galey J, et al. Recombinant human LH supplementation during GnRH antagonist administration in IVF/ICSI cycles: a prospective randomized study. Hum Reprod 2004;19:1979-84.

42. Ben-Ami I, Armon L, Freimann S, Strassburger D, Ron-El R, Amsterdam A. EGF-like growth factors as LH mediators in the human corpus luteum. Hum Reprod 2009;24:176-84.
43. Hsieh M, Zamah AM, Conti M. Epidermal growth factor-like growth factors in the follicular fluid: role in oocyte development and maturation. Semin Reprod Med 2009;27:52-61.

44. Ben-Ami I, Komsky A, Bern O, Kasterstein E, Komarovsky D, Ron-El R. In vitro maturation of human germinal vesicle-stage oocytes: role of epidermal growth factor-like growth factors in the culture medium. Hum Reprod 2011;26:76-81.

45. Lovely LP, Fazleabas AT, Fritz MA, McAdams DG, Lessey BA. Prevention of endometrial apoptosis: Randomized prospective comparison of human chorionic gonadotropin versus progesterone treatment in the luteal phase. J Clin Endocrinol Metab 2005;90:2351-6.

46. Jasinska A, Strakova Z, Szmidt M, Fazleabas AT. Human chorionic gonadotropin and decidualization in vitro inhibits cytochalasin-D-induced apoptosis in cultured endometrial stromal fibroblasts. Endocrinology 2006;147:4112-21.

47. Jurisicova A, Antenos M, Kapasi K, Meriano J, Casper RF. Variability in the expression of trophectodermal markers beta-human chorionic gonadotrophin, human leukocyte antigen-G and pregnancy specific beta-1 glycoprotein by the human blastocyst. Hum Reprod 1999;14:1852-8.

48. Bonduelle ML, Dodd R, Liebaers I, Vansteirteghem A, Williamson R, Akhurst R. Chorionic gonadotrophin-beta messenger-RNA, a trophoblast marker, is expressed in human 8-cell embryos derived from tripronucleate zygotes. Hum Reprod 1988;3:909-14.

49. Lopata A, Hay DL. The surplus human-embryo-its potential for growth, blastulation, hatching, and human chorionic-gonadotropin production in culture. Fertil Steril 1989;51:984-91.

50. Filicori M, Fazleabas AT, Huhtaniemi I, Licht P, Rao CV, Tesarik J, et al. Novel concepts of human chorionic gonadotropin: reproductive system interactions and potential in the management of infertility. Fertil Steril 2005;84:275-84.

51. Han SW, Lei ZM, Rao CV. Treatment of human endometrial stromal cells with chorionic gonadotropin promotes their morphological and functional differentiation into decidua. Mol Cell Endocrinol 1999;147:7-16.

52. Cameo P, Szmidt M, Strakova Z, Mavrogianis P, Sharpe-Timms KL, Fazleabas AT. Decidualization regulates the expression of the endometrial chorionic gonadotropin receptor in the primate. Biol Reprod 2006;75:681-9.

53. d'Hauterive SP, Berndt S, Tsampalas M, CharletRanaud C, Dubois M, Bourgain C, et al. Dialogue between blastocyst hCG and endometrial LH/hCG receptor: which role in implantation? Gynecol Obstet Invest 2007;64:156-60.

54. Gordon UD, Harrison RF, Fawzy M, Hennelly B, Gordon AC. A randomized prospective assessorblind evaluation of luteinizing hormone dosage and in vitro fertilization outcome. Fertil Steril 2001;75:324-31.

55. Matorras R, Prieto B, Exposito A, Mendoza R, Crisol L, Herranz P, et al. Mid-follicular LH supplementation in women 35-39 years undergoing ICSI cycles: a randomized controlled study. Reprod Biomed Online 2009;19:879-87.

56. Fabregues F, Creus M, Penarrubia J, Manau D, Vanrell JA, Balasch J. Effects of recombinant human luteinizing hormone supplementation on ovarian stimulation and the implantation rate in downregulated women of advanced reproductive age. Fertil Steril 2006;85:925-31.

57. Hompes PGA, Broekmans FJ, Hoozemans DA, Schats R, Grp F. Effectiveness of highly purified human menopausal gonadotropin vs. recombinant 
follicle-stimulating hormone in first-cycle in vitro fertilization-intracytoplasmic sperm injection patients. Fertil Steril 2008;89:1685-93.

58. Bosch E, Labarta E, Crespo J, Simón C, Remohí J, Pellicer A. Impact of luteinizing hormone administration on gonadotropin-releasing hormone antagonist cycles: an age-adjusted analysis. Fertil Steril 2011;95:1031-6.

59. Filicori M, Cognigni GE, Pocognoli P, Ciampaglia W, Bernardi S. Current concepts and novel applications of LH activity in ovarian stimulation. Trends Endocrinol Metab 2003;14:267-73.

60. Filicori M, Cognigni GE, Tabarelli C, Pocognoli P, Taraborrelli S, Spettoli D, et al. Stimulation and growth of antral ovarian follicles by selective LH activity administration in women. J Clin Endocrinol Metab 2002;87:1156-61.

61. Filicori M, Cognigni GE, Samara A, Melappioni S, Perri T, Cantelli B, et al. The use of LH activity to drive folliculogenesis: exploring uncharted territories in ovulation induction. Hum Reprod Update 2002;8:543-57.
62. Baruffi R, Mauri AL, Petersen C, Felipe V, Martins A, Cornicelli J, et al. Recombinant LH supplementation to recombinant FSH during induced ovarian stimulation in the GnRH-antagonist protocol: a meta-analysis. Reprod Biomed Online 2007;14:14-25.

63. Gomes MKO, Vieira CS, Moura MD, Manetta LA, Leite SP, Reis RM, et al. Controlled ovarian stimulation with exclusive FSH followed by stimulation with hCG alone, FSH alone or hMG. Eur J Obstet Gynecol Reprod Biol 2007;130:99-106.

64. Al-Inany HG, Abou-Setta AM, Aboulghar MA, Mansour RT, Serour GI. Efficacy and safety of human menopausal gonadotrophins versus meta-analysis recombinant FSH: a mate-analysis. Reprod Biomed Online 2008;16:81-8.

65. Coomarasamy A, Afnan M, Cheema D, van der Veen F, Bossuyt PMM, van Wely M. Urinary hMG versus recombinant $\mathrm{FSH}$ for controlled ovarian hyperstimulation following an agonist long downregulation protocol in IVF or ICSI treatment: a systematic review and meta-analysis. Hum Reprod 2008;23:310-5.
66. Doody K, Devroey P, Gordon K, Witjes H, Mannaerts B. LH concentrations do not correlate with pregnancy in $\mathrm{rFSH} / \mathrm{GnRH}$ antagonist cycles. Reprod Biomed Online 2010;20:565-7.

67. Merviel P, Antoine J-M, Mathieu E, Millot F, Mandelbaum J, Uzan S. Luteinizing hormone concentrations after gonadotropin-releasing hormone antagonist administration do not influence pregnancy rates in in vitro fertilization-embryo transfer. Fertil Steril 2004;82:119-25.

68. Jaakkola T, Ding YQ, Kellokumpulehtinen P, Valavaara R, Martikainen H, Tapanainen J, et al. The ratios of serum bioactive immunoreactive luteinizing-hormone and follicle-stimulatinghormone in various clinical conditions with increased and decreased gonadotropin-secretion-reevaluation by a highly sensitive immunometric assay. J Clin Endocrinol Metab 1990;70:1496-505.

69. Kosmas IP, Zikopoulos K, Georgiou I, Paraskevaidis E, Blockeel C, Tournaye $\mathrm{H}$, et al. Low-dose HCG may improve pregnancy rates and lower OHSS in antagonist cycles: a meta-analysis. Reprod Biomed Online 2009;19:619-30. 